\title{
分散系の比粘度に関するランダム抵抗網モデル
}

\author{
大迫 敏行 \\ 住友金属鉱山侏中央研究所， テ272 市川市中国分3-18-5.
}

\section{Random Resistor Network Model for the Relative Viscosity of Disperse Systems}

\author{
Toshiyuki Osako \\ Central Research Laboratory, Sumitomo Metal Mining Co., Ltd., 3-18-5 Nakakokubun, Ichikawa 272.
}

Received June 23, 1995

\section{SYNOPSIS}

The Random Resistor Network Approach is applied to a modeling of the relative viscosity of disperse systems. A suspension that solid particles are dispersed in a liquid is represented by occupied or empty sites of cubic lattice. The resistivity of the heterogeneous system is equivalent to the viscosity of suspension according to the excitation-response theory. Monte Carlo simulation of zero-shear viscosity was conducted for the varied solids loading and solid/liquid bond resistance. The calculation results exhibit a good agreement with the experimental data obtained before. Bond Resistance and bond probability of particles introduced into the model enables the modeling of the dynamic viscous behavior of suspensions.

KEY WORDS

suspension, zero-shear viscosity, random resistor network, percolation, Monte Carlo simulation

1 はじめに

㸮末射出成形などの粉末成形プロセスでは，粉末粒 子をバインダに分散させた混練物を用いて成形を行う ので，混練物の粘弾性的性質は成形時の流動に大きな 影響を及ぼす。射出成形用混練物をはじめコロイド， 蔣濁液などの分散系では，内部構造が剪断の影響を受 けるので，時間に独立なNewtonの粘性法則は一般に成 立しない，分散系の粘性挙動を記述しようとする試み は古くから数多くなされている．特に零剪断粘度（剪 断速度を0に近づけていったときの極限の粘度）につい ては, Einstein 1)の式を始め, 膨大な数の理論式, 経験 式が提案されている2). 現在では(1)に示すKriegerDougherty3)の式が，広い範国の粒子体積率 $\phi$ に対して よく実験結果に合うとされる4),

$$
\eta_{\mathrm{r}}=(1-\mathrm{c} \cdot \phi)^{-\mathrm{s}}, \mathbf{c}, \mathbf{s} ; \text {; 定数. }
$$

ここで $\eta_{\mathrm{r}}$ は比粘度（分散系の粘度 $\eta$ と媒体の粘度 $\eta_{0}$ の比)である.しかし、これらの式は内部構造や時間 を変数として含まないので，動的な粘度の変化を記述 できない，一方，橴濁液の粘度の時間および剪断速度 依存性を記述しようとする試みもなされている。た えば, Hattoriら5)は粒子クラスタを1次元の数珠型モデ ルで表し、影濁液の粘度を構成要素間の摩擦, 粒子の 凝集速度および前断速度などをパラメータとして時間
の関数として表現するモテルを提案している.このモ テルは，粒子湭度が低く数珠型クラスタを形成しやす い系では有効であるが，一般には粘度の粒子濃度依存 性が現実系と一致しない。

クラスタ形成に基づく物性の変化を取り扱うモテル として浸透 (percolation) 理論がある. 分散系に関して も，樹脂のゲル化現象を中心に浸透理論による矿究は 多くなされているが，粘度については明睹な結果が得 られていないようである6). 本研究では浸透理論の考え 方を適用して分散系のジオメトリをモテル化し，粘度 を表すモデルを提案した．またこのモデルを用いて， 計算機実験により零剪断粘度に及ぼす粒子濃度および 界面抵抗の影響を求めた。ささらに粒子の結合確率を導 入しクラスタの形成・分解のモテル化を試みた.

2 流動度，伝道度、拡散係数の類似

刺激応答理論によれば粘弾性挙動を記述する力学的 モテルと電気的性質を表す諸法則には，形式的な類似 性が存在する。 たとえば， Newtonの粘性法則 $\sigma=\eta$. $\gamma$ には，Ohmの法則 V=R・Iが対応する．ここで応力 $\sigma$, 粘度 $\eta$, 前断速度 $\gamma$ には, 電王 $\mathbf{V}$, 抵抗 $\mathbf{R}$, 電流 $\mathbf{I}$ が対応する. 本モデルではこの関係を用い，ジオメト リに依存する物性值である粘度 $\eta$ 亡抵抗Rは等価である 
と考える.また不規則媒体中の搪散係数は系の伝導度 $\Sigma$ （抵抗 Rの逆数）に等しいことが指摘されている7). したがって，分散系の粘度を求めることは，対㣽る モデルにおいて系の伝導度または拡散係数を求めるこ こに他ならない。このうち伝導度は系のジオメトリが 決まれば一意的に求められ，搪散における醉歩実験の ような多数回の試行を必要としないため，数值実験を 行う場合には有利である.

\section{3ランダム抵抗網モデル}

液相媒体中に固体粒子が分散している系を考える. 各格子点を粒子体皘率 $\phi$ に等しい確率で占有させるこ とにより，液相中にランダムに粒子を分散させる，粒 子の作るクラスタは，隣り合った粒子の結合確率 $\mathrm{p} か ゙ 1$ である時はサイト浸透，p<1の時はサイトーボンド浸透 之なる，一方，空格子点すなわち媒体に着目すると，

媒体の結合確率は常に1である.ここでは粒子クラスタ の形成・分解を扱うので, 占有格子点のサイトーボン ド過程における，空格子点の浸透を考える.

通常の浸透問題では異相間のボンドは考えない。し かし，粘性を考える場合には界面の摩擦抵抗も重要な 役割を果たすと考えられる。また粒子間の摩擦は，す べりを生じる場合と，結合している場合とでは異なる。 占有格子点のボンドーサイト過程では, 格子点間のボン ドは Fig. 1 に示すように，格子点の組み合わせによっ て、(1)液 -液間ボンド, (2)固-液間ボンド, (3)固-固間ボ ンド（すべりを生じる場合）(4)固-固間ボンド（結合し ている場合）の 4 種が考えられる. 上記のように，力 学モデルと電気モデルの形式的類似性から，これを電 気的モテルとして解析してみることは可能であろう. それぞれのボンドの抵抗を $\mathrm{R}_{1} ， \mathrm{R}_{2} ， \mathrm{R}_{3} ， \mathrm{R}_{4}$ とすれば、, 各ボンドをそれぞれの大きさの抵抗をもった導体とし， 液相の浸透を考えることにより，系はランダム抵抗網

(Random Resistor Network:RRN) に置き換えることが できる. それぞれのボンドに抵抁值を与えれば，ある ジオメトリをもつ系の抵抗は一意的に決まる。

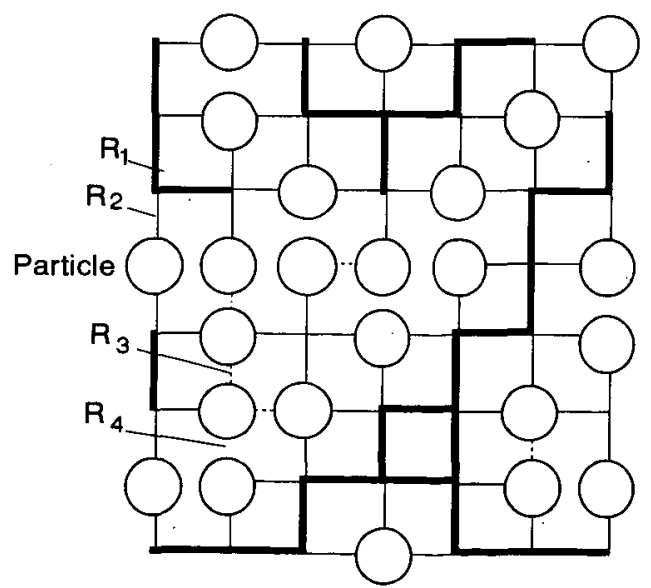

Fig. 1 Random Resistor Network model of a suspension. Four variations of bond between sites have the resisitance, $\mathbf{R} 1 \sim \mathbf{R} 4$, respectively.
このようなRRN問題を含めて 3 次元の浸透現象は一 般に解析的に解くことができない，そこで計算機によ るモンテカルロシミュレーションを行ったＲRNの伝 導度を計算する方法とはいくつか提案されているが, ここでは臨界緩慢化の生じない転送行列法を用い,

Derridaら8)のアルゴリズムに基づいて計算を行った.

\section{1 需剪断粘度}

\section{4 実験および考察}

系を長時間放置し，粒子クラス夕構造が確立してい る状驡 $(\mathrm{p}=1)$ で零剪断粘度について考える. 結合し た粒子間のボンドは流動に奇与しないから， $\mathrm{R}_{\mathbf{4}}=\infty$ とし， 液相間ボンドの抵抗值 $R_{1}=1$ とする. 固-液界面の摩擦抵 抗は, 界面の性質によって変化するので, $\dot{R}_{2}=1 \sim \infty の$ 範囲で変わり得る. また $\mathrm{p}=1$ なので $\mathrm{R}_{3}$ は考えなくてよ い.ここでは $\mathrm{L} \times \mathrm{L} \times \mathrm{N}=16 \times 16 \times 200$ の大きさの立方格 子について, 粒子濃度 $\phi=0 \sim 1 お よ ひ ゙ R_{2}=1 \sim \infty$ 範囲 で計算を行った. Fig. 2 には， $R_{2}=1 ， 10,100 ， \infty$ の 場合について，伝尊度 $\Sigma$ の計算結果を液相量y $(=1-\phi)$ に対して示す.

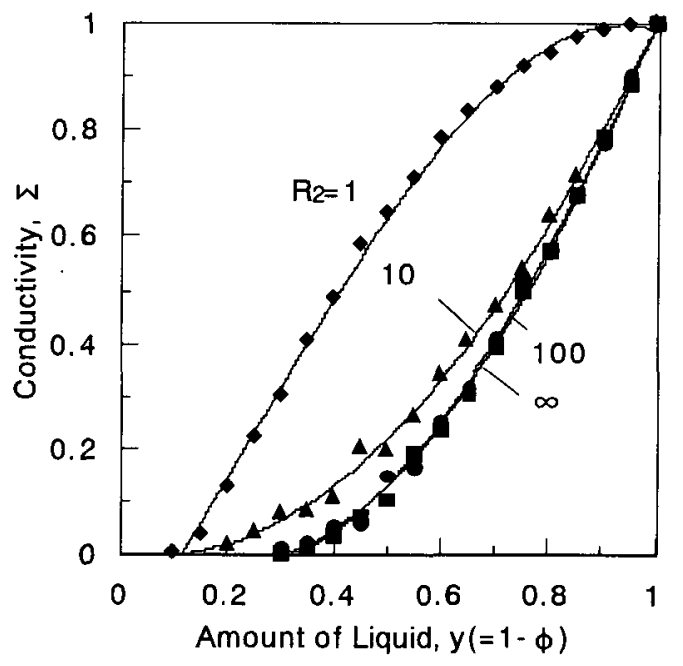

Fig.2 Calculated conductivity, $\Sigma$ vs the amount of liquid of suspension, y. $\phi$ : solid loading, $R_{2}$ : resistance of particle/liquid bond.

yが小さいときには，空格子点クラスタの大きさは有 限に止まり，系は絶縁性である. ある液相量 $\mathrm{y}_{\mathrm{c}}$ (浸透 闎値と呼ばれる）に達したとき, 液相クラスタは無限 遠までつながり，系は導電性となる．これは粘性挙動 において流動が開始することに対応する，y > ycで伝尊 度はyとともに大きくなり，y=1で $\sum=1$ となる， $\mathrm{y}_{\mathrm{c}}$ およ び

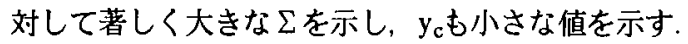
$\mathbf{R}_{2}>100$ ではほとんど $\mathbf{R}_{2}=\infty$ と等しい挙動を示す.

定義から， $\mathbf{R}_{2}=\infty$ の時，液相は単純なサイト浸透とな 
る. 伝導度

$$
\sum \propto\left(\mathrm{y}_{-} \mathrm{y}_{\mathrm{c}}\right)^{\mathrm{t}}
$$

と表される．立方格子のサイト浸透は詳しく調べられ ており，大規模な数値実験から浸透閾值 $\mathrm{y}_{\mathrm{c}}=0.3117$, 臨界指数 $\mathrm{t}=1.8 \sim 2.0$ であるとされている9). 臨界指数 は広い組成範囲で適用されるものではないが，ここで

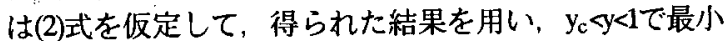
二乗法により浸透䦨值 $\mathrm{y}_{\mathrm{c}}$ よじ臨界指数 $\mathrm{t}$ 計算した。 $\mathrm{y}=1$ で $\Sigma=1$ であるので,

$$
\Sigma=\left(\mathrm{y}_{\mathrm{c}} \mathrm{y}_{\mathrm{c}}\right) \mathrm{t} /\left(1-\mathrm{y}_{\mathrm{c}}\right)^{\mathrm{t}} \text {. }
$$
$\mathrm{y}_{\mathrm{c}}=0.27 \sim 0.30$ の時, $\mathrm{t}=1.82 \sim 1.68$ で，0.999以上の相 関係数が得られた．ここで $\phi=1-\mathrm{y} ，$ 粒子の最大体皘率 $\phi_{\mathrm{m}}=1-\mathrm{y}_{\mathrm{c}}$ ，また抵抗 $\mathrm{R}=1 /$ ¿であるから，これらを(3) 式に代入すれば,

$R=1 / \Sigma=\left(1-\phi / \phi_{m}\right)^{-t}, t=1.68 \sim 1.82$. (4)

一方，Metzner4)によれば(1)式において， $\phi \rightarrow \phi_{\mathrm{m}}$ で $\eta \rightarrow \infty$ であるから, $\mathrm{c}=1 / \phi_{\mathrm{m}}$ であり, このとき $\mathrm{s} 2$ に 近い值となるとされる. したがって，

$$
\eta_{\mathrm{r}}=\eta / \eta_{0}=\left(1-\phi / \phi_{\mathrm{m}}\right)^{-\mathrm{s}}, \mathrm{s} \sim 2,
$$

となり(5)式は(4)式とほぼ等しくなる，すなわち，伝導 度の臨界举動を示す(4)式と，零剪断粘度に関する経験 式である(5)式は形式的に一致する，計算から得られた 結果を $\mathrm{y}_{\mathrm{c}}=0.280(\mathrm{t}=1.80)$ とし， $\eta_{\mathrm{r}}$ と $\phi / \phi_{\mathrm{m}}$ の関係に 直してFig. 3 に示す. Krieger-Doughertyの式とよい一致 が得られることが分かる。

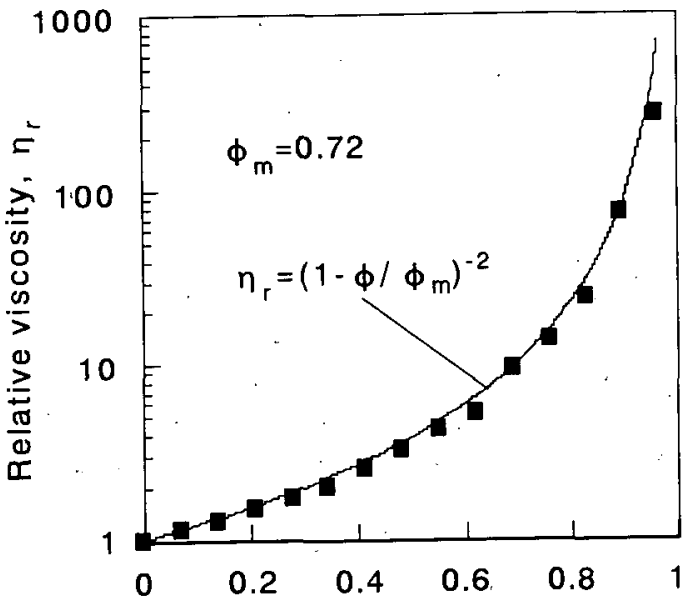

Relative solids loading, $\phi / \phi \mathrm{m}$

Fig.3 Relative viscosity converted from the result of Monte Carlo simulation vs Relative solids loading.

Maximum solids loading $\phi_{\mathrm{m}}=0.72 \quad\left(\mathrm{y}_{\mathrm{c}}=0.28\right)$ was used. Solid line shows Krieger-Dougherty's phenomenological formula.

また(5)式を展開し， $\phi \rightarrow 0$ の希薄濃度領域で1 次項ま でとると，Einsteinの式 1)と同形の1次式が得られる。

$$
\begin{aligned}
\eta_{\mathrm{r}}(\Delta \phi) & =\eta_{\mathrm{r}}(0)+\mathrm{d} \eta_{\mathrm{r}} / \mathrm{d} \phi(0) \cdot \Delta \phi \\
& =1+\mathrm{s} \cdot \Delta \phi / \phi_{\mathrm{m}}
\end{aligned}
$$

ここで，上記の $\mathrm{s}(=\mathrm{t})=1.80 ， \phi_{\mathrm{m}}=1-\mathrm{y}_{\mathrm{c}}=0.720$ を用いれ ば,

$$
\eta_{\mathrm{r}}=1+2.5 \Delta \phi
$$

となり, Einsteinの式における2.5と等しい係数が得ら れる。

以上のように，ランダム抵抗網モデルに基つく粘性 モテルは単純であるが，従来提出されている笭剪断粘 度の絬果とよく一致する。なおここでは，粘性挙動と 伝導度との類似性，および数值実験の有效性を検証す るために，Krieger-Doughertyの式と伝導度の臨界挙動 の形式および指数の比較を行った．しかし，本研究に おける数值実験は臨界指数を前提とするものではなく， むしろyがy $\mathrm{c}$ から遠く，解析的な議論ができない条件下 でも粘度が求められることに特徽があると考える.

\section{2 粘度に及ぼす粒子結合率の影響}

分散系の粘度の時間的変化は，粒子間相互作用によ るクラスタの形成および擋拌によるその分解などに よって生じる．ランダム抵抗網モテルにおいて，結合 確率 $\mathrm{p}$ 導入することにより，クラスタの形成・分解 を表すことを試みた

簡単のために，粒子の分布自身は時間平均的に一定 (ランダム分布)であるとし，凝集・擋找によって生 じる近接粒子の:「結合」せ「すべり」の状態変化を粒 子クラスタのボンドーサイト過程として表す，結合状態 を表す $\mathrm{R}_{4}$ ボンドの割合を結合確率 $\mathrm{p}$ として，粒子クラ ス夕分布に対して前節と同様に系の伝導度を計算する ことにより，比粘度 $\eta_{\mathrm{r}}$ を $\mathrm{p}$ 関数として求めることが できる.ここでは，種々の粒子量に対して，pを0〜1の 範用で変化させて計算を行った．この場合には $R_{2}, R_{3}$ の值が必要となるが, Fig. 4には， $y=0.4, R_{2}=100$, $\mathbf{R}_{3}=1,10,100$ として計算を行った結果を示す.

クはpとともに増加するが，その様子はR ${ }_{3}$ の值に よって大きく変わる， $\mathbf{R}_{3}=10,100$ の場合にはp による $\eta_{r}$ の変化は小さく，また分散が非常に大きい， $\mathrm{R}_{3}=1$ で は， $\eta_{\mathrm{r}}$ はp とともに增加する。

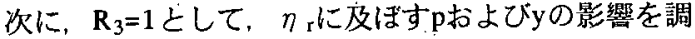
べた結果を Fig.5に示す， $\mathrm{y}=0.5$ と粒子量が少ないとき には，pによる $\eta_{\mathrm{r}}$ の変化は小さいが，粒子量が多いy= 0.3 では, $\mathrm{p}$ の増加と共に $\eta_{\mathrm{r}}$ は急激に大きくなる．分散 系に前断を加えることによって粘度が低下するチキソ トロピー現象は，粒子クラスタ構造の分解によると考 えられる.ランダム抵抗網モデルに結合確率政導入す ることによって，このような現象もモテル化できる可 能性がある。なおFig.4,5において， $\mathrm{R}_{3}$ が小さい場合や 粒子量が多い場合に計算結果の変動が大きくなった。 これらの条件では計算結果である伝導度が非常に小さ い値であり，逆数である粘度の変動が大きくなる，用 いた格子が比較的小さいことによるのか，本質的なむ のなのか，アルゴリズムを含めて今後さらに検討する 必要がある. 


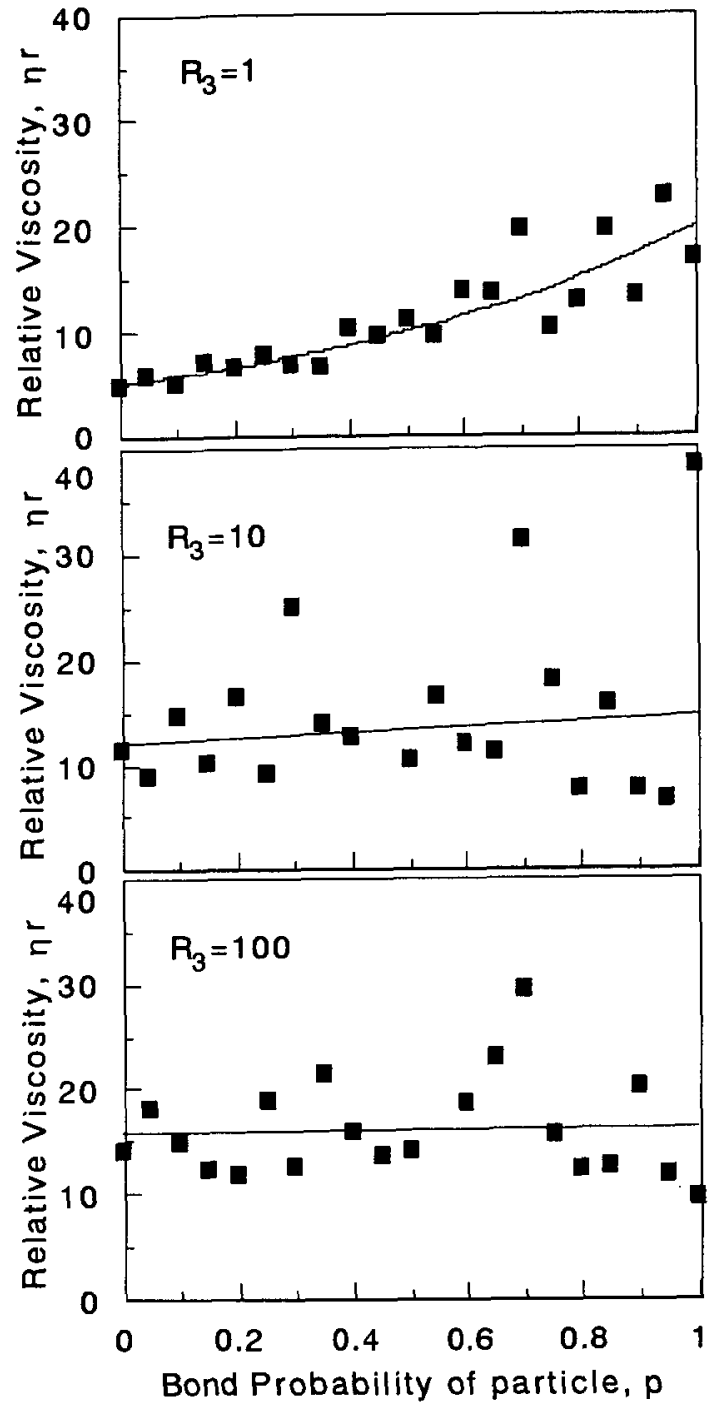

Fig. 4 The effects of bond probability on the relative viscosity at the amount of liquid, $y=0.4$. The resistance of the bond between slipping particles, $R_{3}$ was varied.

このモデルにおいて，粒子結合確率pを粒子の凝集速 度, 剪断速度, 時間の関数として表せば, 分散系の動 的粘性挙動を記述できると考えられる. 凝集モテルに ついては，希薄系におけるSmoluchowskiの方程式を始 め. 多くの検討がなされている、Hattoriら5)は，擋抖に よる機械的エネルギーと粓子の表面エネルギーに基づ いた凝集速度式を用いて，粒子結合数を時間の関数と して表している．同様の議論が本モテルにも適用され 得ると考えるが，その場合，本モテルで用いた準静的 クラスタ配置の妥当性についても検証する必要があろ う. またここでは $\mathbf{R}_{2} ， \mathbf{R}_{3}$ を適宜に決めたか，実際の分 散系の粘度湘定から $\mathbf{R}_{2} ， \mathbf{R}_{3}$ を決定する方法などを確立 する必要がある.

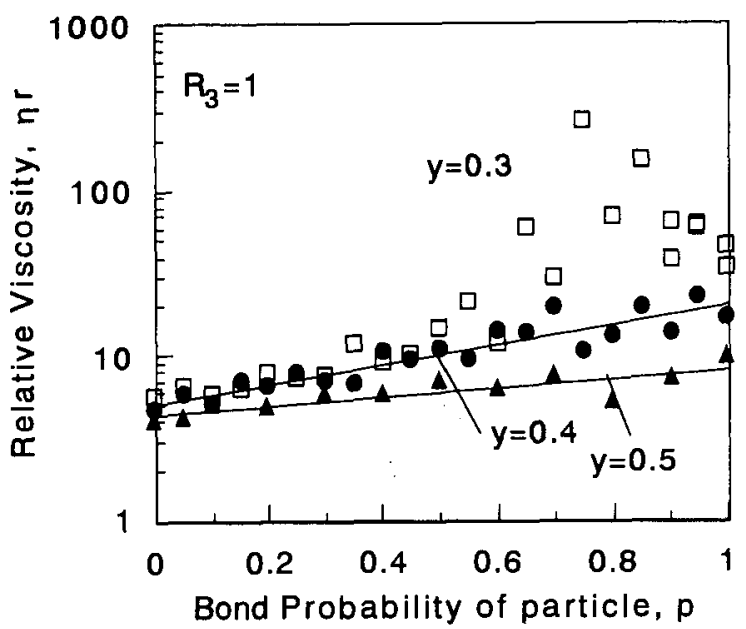

Fig.5 The effect of bond probability, $p$ and the amount of liquid, $y$ on the relative viscosity for $R_{3}=1$.

5 まとめ

粉末プロセスとして広く用いられる分散系の粘性挙 動を表すモデルとして，ランダム抵抗網を用いたモデ ルを検討した。

(1) 固体粒子と液相媒体からなる分散系を浸透理論に基 づいてモデ化した．各ボンドをサイトの種類に応じ た抵抗を持つ導体と考えることにより，系の比粘度は ランダム抵抗網の抵抗値問題に置き換えることができ る.

(2)このモテルを用いてモンテカルロ法により分散系の 比粘度を求めた，得られた計算結果はこれまで知られ ている零前断粘度式とよく一致した。

(3) 界面抵抗と粒子結合確率を考慮することにより，系 の内部構造を表すパラメータをモテルに導入した．系 の伝導度は界面抵抗と粒子結合確率の值によって変わ る. このモテルを用いることにより，分散系の動的な 粘性挙動を記述できる可能性があると考えられる.

\section{文 献}

1) A. Einstein: Annal. Physik, 19 (1906), 289.

2) I. R. Rutgers: Rheol. Acta, 2(1962), 202.

3) I. M. Krieger, T. J. Dougherty: Trans. Soc. Rheol., 52(1959), 137.

4) A. B. Metzner: J. Rheology: 29 (1985), 739.

5) K. Hattori, K. Izumi: J. Dispersion Sci. Tech., 3(1982), 129.

6) D. Stauffer, A. Coniglio, M. Adam: Adv. Poly. Sci., 44(1982), 103.

7) P.G. de Gennes: La Recherche, 7(1976), 919.

8) B. Derrida, J. Vannimenus: J. Phys. A, 15(1982), L557.

9) J. G. Zabolitzky: Rhys. Rev. B, 30(1984), 4077. 